\title{
Anti-American Sentiment and America's Perceived Intent to Dominate: An 11-Nation Study
}

\author{
Peter Glick, Susan T. Fiske, Dominic Abrams, Benoit Dardenne, Maria Cristina \\ Ferreira, Roberto Gonzalez, Christopher Hachfeld, Li-li Huang, Paul Hutchison, \\ Hyun-Jeong Kim, Anna Maria Manganelli, Barbara Masser, Angelica \\ Mucchi-Faina, Shinya Okiebisu, Nadim Rouhana, José L. Saiz, Nuray \\ Sakall1-Ugurlu, Chiara Volpato, Mariko Yamamoto, and Vincent Yzerbyt
}

\begin{abstract}
Perceptions of America as a powerful but malevolent nation decrease its security. On the basis of measures derived from the stereotype content model (SCM) and image theory (IT), 5,000 college students in 11 nations indicated their perceptions of the personality traits of, intentions of, and emotional reactions to the United States as well as their reactions to relevant world events (e.g., 9/11). The United States was generally perceived as competent but cold and arrogant. Although participants distinguished between the United States' government and its citizens, differences were small. Consistent with the SCM and IT, viewing the United States as intent on domination predicted perceptions of lack of warmth and of arrogance but not of competence and status. The discussion addresses implications for terrorist recruitment and ally support.
\end{abstract}

Hostile attitudes toward the United States, its policies, and actions are by no means confined to those who seek to attack America. Paler versions of anti-American hostility are also prevalent among citizens of nations, such as England, that have historically been close allies (Pew Global Attitudes Project, 2004). Both more and less extreme anti-American attitudes undermine America's security. The former increase the threat of terrorism, whereas the latter decrease the likelihood of cooperation with other nations to construct coordinated policies that enhance security.

It is therefore vital to understand the nature, the tenor, and the content of anti-American attitudes. A particularly important (as well as convenient) group to examine is the educated youth of other nations, for two reasons. First, the leaders of terrorist organizations are typically well-educated-terrorist attacks are generally conceived and often carried out by young men who were radicalized in their college years (Amant, 2001). Second, although it is a cliché to say that "the youth are the future," it is also true. The educated elite typically exert more political influence and provide the ranks from which future political leaders emerge. The current

Correspondence should be addressed to Peter Glick, Department of Psychology, Lawrence University, PO Box 599, Appleton, WI 54912-0599. E-mail: glickp@lawrence.edu study examines attitudes of college students in 11 geographically and culturally diverse nations toward the United States .

Despite an initial outpouring of sympathy after the 9/11 attacks, global opinion polls have since documented increasingly hostile attitudes toward the United States (Pew Global Attitudes Project, 2002, 2004). The research presented here supplements such opinion polls by examining the psychological characteristics that people in other nations assign to the United States (its government and citizens). We do not attempt to assess the validity of current attitudes toward the United States, which is a task better suited to political commentators. Rather, we seek to define the general content or "psychological profile" of people's image of the United States. More specifically, we sought to: (a) develop a more detailed picture of the traits and motivations attributed to, and the emotions felt toward, the United States; (b) determine the degree to which people in other nations differentiate between the U.S. government and its citizens; and (c) examine how respondents' attitudes are influenced by their perceptions of the United States' goals and intentions.

Our approach was informed by two recent models of intergroup relations, the stereotype content model (SCM; Fiske, Cuddy, Glick, \& Xu, 2002) and image theory (IT; Alexander, Brewer, \& Herrmann, 1999), which make predictions about the content of group stereotypes or images. Both 
theories suggest that the structural factors of a group's status and power combined with its perceived orientation toward other groups determine stereotypes of the group.

The SCM predicts that status and power elevate a group's perceived competence but that the quality of its perceived interdependence with other groups (cooperative or competitive) determines the group's perceived warmth. The SCM predicts that if it is perceived as cooperative, a high-status group will be viewed as competent and warm, resulting in admiration. If, however, a high-status group is perceived as having competitive goals, it will be viewed as competent and cold, generating resentment. Although IT does not explicitly distinguish between underlying dimensions of competence and warmth, it also suggests that a high-status, powerful group will either be viewed as an ally (trustworthy, well-intentioned, admirable) or as an imperialistic enemy (arrogant, manipulative exploiters). The latter image is similar to the SCM characterization of competitive, high-status groups (competent but cold or ill-intentioned).

In short, both the SCM and IT predict that the prevailing image of high-status groups depends on whether those groups are viewed as having compatible or exploitive goals. There are some differences in the specific dimensions these theories concentrate on, so that some measures used here were inspired by one of the theories and others by both. The purposes of the current study, however, are not to provide a critical test between the theories but to take advantage of their complementary and overlapping predictions to more completely understand images of the United States.

The consequences of viewing a group as both powerful and malevolent are profound. Aggression toward such groups, even if preemptive, can be psychologically justified as a matter of self-defense. Although open state-initiated hostility toward powerful nations may be inhibited by fear of retaliation, terrorist groups do not experience such inhibition, relying instead upon presenting no fixed target that can be easily retaliated against. If there is a widespread consensus within a nation that the United States is not only powerful but seeks to dominate, the recruitment of terrorists is undoubtedly aided and the ability of terrorists to count on the passive assistance of the populace (e.g., sheltering them) enhances their ability to operate effectively.

The current study examines the attitudes of over 5,000 people (predominantly college students) in 11 geographically and culturally diverse nations, collected shortly after the United States' invasion of Afghanistan but before the invasion of Iraq. In contrast to the Pew polls (Pew Global Attitudes Project, 2002, 2004), which measure general attitudes about the United States (e.g., an overall favorability rating), the current survey examines the psychological profile of impressions of the United States in more detail, by using theoretically derived measures from the SCM and IT. These measures include: (a) trait ratings (from the SCM: competence and warmth; from IT: arrogance), (b) subjectively positive and negative emotions specified by the SCM (admiration, contempt, envy), (c) perceptions of underlying goals (domination vs. promotion of human rights) and attitudes (belief in the superiority of the "American way of life") toward other nations, (d) status and power (resources, military, and economic power, social well-being), (e) reactions to world events (the 9/11 attacks and the subsequent invasion of Afghanistan).

In addition to providing a more psychologically nuanced, in-depth profile of attitudes about the United States, the current study is grounded in psychological theory. Specifically, the SCM suggests that a group's status predicts its perceived competence, whereas perceptions of the group's orientation toward others (cooperative vs. competitive) predicts its perceived warmth. As Asch (1946) noted, the Gestalt produced by competent-warm and competent-cold impressions are radically different. The former produces favorable emotions (e.g., admiration, respect) and benign perceptions of the target group's intentions. In contrast, the latter yields strongly negative emotions (e.g., resentment) and suspicions of nefarious intent. Because the power of the United States is generally undisputed, the SCM predicts that the United States will be perceived as competent, even among those who have strongly negative emotions toward it. In contrast, perceptions of the United States' orientation toward other nations ought to predict whether the United States is perceived as warm (or not). Similarly, IT proposes that high-status, competitive groups will be viewed as arrogant imperialists. Both the SCM and IT suggest that whether the United States is viewed as cooperative or competitive will determine whether respondents have favorable or unfavorable evaluations of the United States' actions.

In short, the SCM and IT together suggest that perceiving the United States as seeking to dominate (rather than to help) other nations (i.e., as negatively interdependent with the well-being of other nations) will predict more negative reactions toward the United States on (a) trait ratings (from SCM: low ratings on warmth; from IT: high ratings on arrogance), (b) emotion ratings (from SCM: less admiration, more contempt and envy), and (c) evaluations of actions (e.g., the invasion of Afghanistan). In contrast, because the SCM predicts that perceived power, status, and competence are independent from perceived cooperativeness-competitiveness and warmth, perceptions of the United States' dominative intentions were expected to be unrelated to ratings on status and competence-related dimensions (competence, resources, and power).

Finally, we sought to determine the degree to which people in other nations distinguish between the U.S. government and its citizens. Although commentators (e.g., Friedman, 2002) have suggested that citizens of other nations regularly make such distinctions, psychological theories of intergroup attitudes typically assume that groups and their members are perceived similarly. Thus, some sections of the questionnaire (depending on random assignment) targeted perceptions of either the U.S. government or its citizens. 


\section{METHOD}

\section{Nations and Samples}

A total of 5,109 respondents (both men and women) in 11 countries (Australia, Belgium, Brazil, Chile, England, Israel, Italy, Japan, Korea, Taiwan, and Turkey) completed a questionnaire assessing attitudes toward the United States. For the Israeli sample, Palestinian and Jewish citizens were treated as separate samples, yielding a total of 12 samples. Sample sizes ranged from 140 to 1,260 (with most samples comprising 200 to 600 respondents).

In some cases, samples were collected in different locations within a country and were then combined. Neither the respondents nor the countries were randomly selectedtherefore the samples cannot be presumed to be a representative of the country in which they were gathered. Respondents were almost exclusively college students. Although the nations were not randomly chosen, they are politically, culturally, and geographically diverse.

\section{Questionnaire and Procedure}

Early in 2002 (after the 9/11 attacks and the invasion of Afghanistan but before the second Gulf War), participants were asked to take part in a survey of attitudes toward the United States, typically in a classroom context. Those who agreed were randomly assigned to receive one of two versions of the questionnaire: In one version, the first section asked specifically about either the U.S. government or its citizens. In both cases, the remainder of the questionnaire asked respondents to consider the United States as a whole (its government, citizens, and culture). For multiple-item scales, principal components factor analyses with varimax rotation were conducted within each of the 12 samples. Items that loaded on a common factor for at least 8 of the 12 samples were grouped together.

In the initial sections of the survey, participants rated the personality traits of, their emotions toward, and the goals and attitudes of (depending on random assignment) either the U.S. government or its citizens.

Traits. Participants rated the degree to which they perceived 19 traits to be characteristic of either the U.S. government or its citizens by using a 5-point Likert-type scale ranging from 1 (not at all characteristic) to 5 (extremely characteristic). These included traits that have been extensively pretested in prior SCM work, both in the United States (Fiske et. al. 2002) and across the globe (Cuddy et al., 2005) to represent the dimensions of warmth and competence. Additionally, as suggested by IT, traits related to arrogance were also assessed. On the basis of factor analyses within each national sample, the traits formed three scales: (a) Warm: good natured, trustworthy, sincere, friendly, warm, well-intentioned (within-sample alphas ranged from .69 to .84); (b)
Competent: competent, intelligent, confident, skillful, efficient, capable (within-sample alphas ranged from .70 to .82); (c) Arrogant: selfish, power hungry, aggressive, arrogant, deceitful (within-sample alphas ranged from .63 to .83).

Emotions. Participants rated the degree to which they typically felt each of 21 emotions designed to assess the four SCM clusters of admiration, contempt, envy, and pity toward either the U.S. government or its citizens on a 5-point Likert-type scale ranging from 1 (not at all) to 5 (extremely). On the basis of factor analyses within each national sample, the traits formed three scales: (a) Contempt: disgust, uneasiness, anger, frustration, indignation, resentment, hatred, ashamed, humiliation, contempt (within-sample alphas ranged from .85 to .93); (b) Admiration: admiration, respect, fondness, pride, inspired, sympathy (within-sample alphas ranged from .72 to .85); (c) Envy: envy, jealousy (within-sample alphas ranged from .51 to .80 , with the exception of Taiwan [.37]). The items intended to assess pity (pity, sympathy) did not consistently correlate with each other in the various national samples (instead, sympathy loaded on the Admiration factor). Because of the failure to find a reliable scale and because pity is not a predicted emotion toward a high status group (in fact, ratings of pity were uniformly low), this emotion is excluded from further analyses.

Goals, motivations, and attitudes toward other nations. Respondents evaluated 15 statements about the goals, motivations, and attitudes of the United States-either government or citizens - toward other nations on a 5-point Likert-type scale ranging from 1 (not at all characteristic) to 5 (extremely characteristic). On the basis of factor analyses within each national sample, the statements formed three scales (the gist of each item is listed): (a) Domination: want to dominate politically and economically, only concerned with enhancing own wealth, no concern for what is best for other nations, want to exploit others as cheap labor, want to exploit natural resources of other nations, want to maintain inequality between nations to keep power, are responsible for problems in other nations, support dictators so long as they support the United States (within-sample alphas ranged from .77 to .89); (b) Human Rights: promote freedom for all, want human rights for all, promote democracy for all, promote prosperity for all, care about justice in other parts of the world (within-sample alphas ranged from .69 to .86); (c) Belief in Own Superiority: believe that own way of life is superior to all others, believe that U.S. citizens are superior to all others (within-sample alphas ranged from .64 to .86).

For the concluding sections of the survey, respondents were asked to "Think about the United States as a whole-its people, government, culture, etc." All participants received identical concluding sections in both versions of the questionnaire. 
Resources, power, and social well-being. Respondents rated how the United States compares with other nations on 10 attributes related to economic and technological resources, social well-being, and military-political power by using a -3 (United States is far behind other nations) to +3 (United States is far ahead of other nations) scale. On the basis of factor analyses within each national sample, the attributes formed three scales: (a) Resources: economic resources, industrial development, technological capabilities (withinsample alphas ranged from .52 to .71); (b) Power: military power, world political power (within-sample alphas ranged from .40 to .60, with the exception of South Korea [.29]); and (c) Social Well-Being: quality of life, education, eradicating poverty, access to health care, happiness of citizens (withinsample alphas ranged from .73 to .82).

Perceptions of the invasion of Afghanistan. Participants rated their agreement or disagreement with five statements about the reasons for and the justification of the United States' military actions in Afghanistan on a 5-point Likert-type scale ranging from 1 (strongly disagree) to 5 (strongly agree). Factor analyses within each national sample revealed two clusters: (a) Justified Response: United States had a right to attack the Taliban, United States has the right to kill Osama bin Laden (within-sample alphas ranged from .49 to .73); (b) Ulterior Motives: invasion was an excuse to attack Afghanistan for other reasons, attack reflects general hostility of the United States toward Islam, United States has no intention of rebuilding Afghanistan after the war (within-sample alphas ranged from .40 to .72 ).

Perceptions of 9/11 attacks. Respondents rated their level of agreement with nine statements about the causes of and their own responses to the $9 / 11$ attacks on a 5-point Likert-type scale ranging from 1 (strongly disagree) to 5 (strongly agree). These items formed a single scale coded to indicate upset over 9/11 attack. The items included: attack was completely unjustified, attack was planned by Osama bin Laden, I felt angry and furious at the attackers, I was very upset over the suffering of victims, attack can only be described as terrorism. An additional four items were reverse scored: attack was caused by how the United States treats other nations, I sympathize with the anger of those who would attack the United States, I was satisfied to see that the United States not immune to attack, attack happened mainly because the United States favors Israel (within-sample alphas ranged from .49 to .78 ).

\section{RESULTS}

\section{Trait Perceptions of the U.S. government and Its Citizens}

How did respondents view the personality traits of the U.S. government and its citizens? The SCM suggests that high-status groups are generally viewed as competent. Perceptions of warmth and arrogance, in contrast, were predicted to vary, depending on whether respondents perceived the United States to have a cooperative or dominative orientation toward other nations, with more favorable impressions on these traits occurring when there is perceived cooperation. A 2 (target: government, citizens) $\times 3$ (trait dimension: warmth, competence, arrogance) analysis of variance (ANOVA) was performed within each national sample, with trait dimension as a repeated measures factor (see Table 1 for means). In all 12 samples, this analysis revealed a trait main effect (all $F \mathrm{~s} \geq 47.92, p<.001$ ); in 11 of 12 samples (the exception being South Korea), there was a significant Trait $\times$ Target interaction (all significant $F \mathrm{~s} \geq$ 4.66, $p<.01)$.

TABLE 1

Mean Values for Perceived Traits of the Government and Citizens of the United States

\begin{tabular}{|c|c|c|c|c|c|c|c|c|c|}
\hline \multirow[b]{2}{*}{ Nation } & \multicolumn{3}{|c|}{ Warmth } & \multicolumn{3}{|c|}{ Competence } & \multicolumn{3}{|c|}{ Arrogance } \\
\hline & Government & Citizens & $t$ & Government & Citizens & $t$ & Government & Citizens & $t$ \\
\hline Australia & 2.88 & 3.08 & $-1.85^{*}$ & 3.71 & 3.63 & .84 & 3.84 & 3.58 & $2.21 * *$ \\
\hline Belgium & 2.49 & 2.83 & $-4.64 * * *$ & 3.19 & 3.24 & -.65 & 3.63 & 3.42 & $2.15 * *$ \\
\hline Brazil & 2.13 & 2.34 & $-3.00 * * *$ & 3.83 & 3.73 & 1.46 & 3.97 & 3.83 & $1.96^{*}$ \\
\hline Chile & 2.43 & 2.54 & $-2.96 * * *$ & 3.77 & 3.77 & -.01 & 3.68 & 3.49 & $4.41 * * *$ \\
\hline England & 2.69 & 3.37 & $-8.98 * * *$ & 3.54 & 3.56 & -.42 & 3.90 & 3.46 & $5.71 * * *$ \\
\hline Italy & 2.47 & 2.74 & $-2.92 * * *$ & 3.72 & 3.55 & $1.85^{*}$ & 3.60 & 3.39 & $2.65 * * *$ \\
\hline Japan & 2.48 & 3.03 & $-7.20 * * *$ & 3.69 & 3.48 & $2.83 * * *$ & 3.96 & 3.72 & $2.84 * * *$ \\
\hline Jewish Israeli & 2.94 & 3.20 & $-3.86^{* * *}$ & 3.60 & 3.34 & $5.10 * * *$ & 3.73 & 3.12 & $9.07 * * *$ \\
\hline Korea & 2.07 & 2.09 & -.14 & 3.65 & 3.56 & .84 & 4.20 & 4.13 & .70 \\
\hline Palestinian Israeli & 1.66 & 2.10 & $-5.57 * * *$ & 3.45 & 3.45 & .02 & 4.36 & 3.97 & $4.84 * * *$ \\
\hline Taiwan & 3.09 & 3.28 & $-2.18 * *$ & 3.98 & 3.74 & $3.60 * * *$ & 3.78 & 3.53 & $3.07 * * *$ \\
\hline Turkey & 1.96 & 2.53 & $-8.61 * * *$ & 3.91 & 3.39 & $9.43 * * *$ & 4.06 & 3.54 & $8.00 * * *$ \\
\hline$M$ & 2.41 & 2.75 & & 3.64 & 3.51 & & 3.92 & 3.61 & \\
\hline
\end{tabular}

Note. All ratings were made on a scale ranging from 1 (not at all) to 5 (extremely).

$* p<.10 . * * p<.05 . * * * p<.01$ 
The trait main effect generally occurred because respondents rated the United States (government and citizens averaged together) as low in warmth but high in competence and arrogance. In other words, traits attributed to the United States typically fit into the SCM's high-competence, low-warmth stereotype cluster and IT's imperialist image. In all samples, the United States was rated significantly lower on warmth as compared to both competence (all $t \mathrm{~s} \leq-10.16$, $p<.001$ ), and to arrogance (all $t \mathrm{~s} \leq-5.93, p<.001$ ). Participants also rated the United States as higher on arrogance than on competence in 8 of 12 samples (all significant $t \mathrm{~s} \geq 2.19, p$ $<.05$ ), whereas the United States was characterized as higher in competence than in arrogance in only two samples (Chile, Taiwan; both $t \mathrm{~s} \geq 3.79, p<.001)$. In general, however, differences between ratings of competence and arrogance were not large-both traits were generally seen as characterizing the United States much more than warmth.

Overall, the results were more consistent than they were different across nations. Participants generally viewed the United States (both its citizens and government) as competent but arrogant and as not being particularly warm. In general, respondents typically rated the United States close to the midpoint (2.5) of the 1 to 5 scale for warmth and much higher than the midpoint on competence and arrogance.

The main effect must be interpreted, however, in light of the significant Trait $\times$ Target interactions. These interactions occurred because although characterizations of the government and citizens of the United States showed the same general pattern, the government was rated in a more extreme manner. Specifically, the U.S. government (in comparison to its citizens) was viewed as relatively more competent and arrogant but less warm. The most consistent differences between ratings of the government and citizens occurred for warmth and arrogance. As Table 1 (which provides $t$ tests) shows, participants rated U.S. citizens as significantly warmer and significantly less arrogant than their government in 10 of 12 samples (and, for both traits, a marginally significant difference occurred in the same direction in 1 of the 2 remaining samples). Few differences occurred for competence ratings, which were significantly higher for the U.S. government than citizens in only four samples (with marginal significance in one other nation).

In summary, there was consensus that the U.S. government is more arrogant and less warm than its citizens, suggesting greater liking for the people of the United States than for their government. Note, however, that even when consistent and statistically significant, differences between ratings of the U.S. government and its citizens were of relatively small magnitude. Overall, both were characterized as high in competence and arrogance but low in warmth.

\section{Emotions Toward the U.S. Government and Its Citizens}

What emotions did respondents report feeling toward the United States? The SCM suggests that a high-status nation ought to evoke admiration if it is viewed as cooperative, but that it should elicit envious resentment if it is viewed as intent on dominating others. Envy, however, is a socially undesirable emotion and implies a negative self-image for the perceiver, who is implicitly admitting that he or she lacks a quality the envied other has (Smith, 1991). Therefore, selfreport measures are unlikely to elicit high envy ratings (Spears \& Leach, 2004). Instead, envy may be expressed as an ambivalent combination of admiration and contempt. A 2 (target: government, citizens) $\times 3$ (emotion: admiration, contempt, envy) ANOVA was performed within each national sample, with Emotion as a repeated measures factor (see Table 2 for means). In all 12 samples, this analysis revealed an emotion main effect (all $F \mathrm{~s} \geq 9.81, p<.001$, with an Emotion

TABLE 2

Mean Values for Emotions Toward the Government and Citizens of the United States

\begin{tabular}{|c|c|c|c|c|c|c|c|c|c|}
\hline Nation & \multicolumn{3}{|c|}{ Admiration } & \multicolumn{3}{|c|}{ Contempt } & \multicolumn{3}{|c|}{ Envy } \\
\hline Australia & 2.54 & 2.68 & -1.09 & 2.29 & 2.04 & $1.91 *$ & 1.75 & 1.75 & .00 \\
\hline Brazil & 2.32 & 2.37 & -.74 & 2.37 & 2.06 & $3.82 * * *$ & 1.68 & 1.56 & 1.35 \\
\hline Chile & 2.05 & 2.02 & -.78 & 1.97 & 1.75 & $4.76^{* * *}$ & 1.76 & 1.68 & 1.60 \\
\hline England & 2.19 & 2.61 & $-4.68 * * *$ & 2.48 & 2.01 & $4.70 * * *$ & 1.60 & 1.78 & $-1.79 *$ \\
\hline Jewish Israeli & 2.46 & 2.48 & -.20 & 2.52 & 2.08 & $5.16^{* * *}$ & 2.11 & 1.98 & 1.44 \\
\hline Korea & 2.15 & 2.14 & .17 & 3.01 & 3.07 & -.45 & 2.88 & 2.92 & -.23 \\
\hline Palestinian Israeli & 1.70 & 1.98 & $-4.02 * * *$ & 3.77 & 3.03 & $7.46 * * *$ & 2.38 & 2.18 & 1.60 \\
\hline Taiwan & 3.26 & 3.28 & -.19 & 2.38 & 2.41 & -.32 & 2.98 & 2.96 & .18 \\
\hline Turkey & 2.30 & 2.38 & -1.12 & 2.70 & 2.23 & $6.31 * * *$ & 2.64 & 2.51 & 1.35 \\
\hline$M$ & 2.33 & 2.44 & & 2.50 & 2.22 & & 2.12 & 2.11 & \\
\hline
\end{tabular}

Note. All ratings were made on a scale 1 (not at all) to 5 (extremely).

$* p<.10 . * * p<.05 . * * * p<.01$. 
$\times$ Target interaction occurring in 9 of the 12 samples (all significant $F \mathrm{~s} \geq 3.98, p<.05)$. The interaction was marginally significant in 1 additional sample (Australia: $F=2.58, p<$ .10 ), and it was nonsignificant in 2 samples (South Korea and Taiwan).

The emotion main effect generally occurred because respondents expressed more admiration than contempt and more contempt than envy toward the United States (government and citizens averaged together). Admiration ratings were generally higher than ratings for contempt ( 8 of 12 samples: $t \mathrm{~s} \geq 2.10, p<.05$ ) and for envy (9 of 12 national samples: $t \mathrm{~s} \geq 4.75, p<.001)$. In turn, contempt ratings were typically higher than ratings for envy ( 8 of 12 samples: $t \mathrm{~s} \geq 2.33$, $p<.05)$. There were some exceptions to these general trends: Respondents expressed more contempt than admiration in 3 samples (Palestinians in Israel, South Korea, Turkey: $t \mathrm{~s} \leq$ $-2.52, p<.001)$, more envy than admiration in the same 3 samples $(t \mathrm{~s} \leq-7.28, p<.001)$, and more envy than contempt in only 1 national sample (Taiwan: $t=-11.68, p<.001$ ). In summary, the United States was admired slightly more than it was held in contempt (though both sets of ratings typically were around the midpoint of the 1 to 5 scale). Envy ratings were usually significantly lower than admiration and contempt ratings.

The Emotion $\times$ Target interactions occurred becauseconsistent with trait rating differences- the U.S. government was generally held more in contempt and admired less than its citizens, whereas respondents expressed similar levels of envy toward both the government and citizens. Contrasts are reported in Table 2. Respondents expressed significantly more contempt for the U.S. government than for its citizens in 8 of 12 samples (with marginal significance in the same direction in 2 other samples). Although participants typically expressed more admiration for U.S. citizens than for the government, this difference was significant in only 4 of 12 sam- ples. There was only one sample in which participants expressed different amounts of envy (Japanese participants expressed greater envy toward U.S. citizens than toward the government).

In summary, the U.S. government generally was held more in contempt than U.S. citizens, and, in a few samples, the government was admired less than U.S. citizens. Overall, mean ratings of both admiration and contempt typically hovered around the midpoint of the scale, with a notable exception-Palestinians in Israel expressed a particularly high degree of contempt and low amount of admiration for the United States, especially its government.

\section{Perceived Goals and Attitudes of the U.S. Government and Its Citizens}

What goals and attitudes did respondents attribute to the government and citizens of the United States? We examined both negative (domination, being convinced of own superiority) and positive (concern for human rights) goals and attitudes. A 2 (target: government, citizens) $\times 3$ (goals-attitudes: desire to dominate, concern for human rights, belief in own superiority) ANOVA was performed within each sample, with Goals-Attitudes as a repeated measures factor (see Table 3 for means). In all samples, this analysis revealed a Goals-Attitudes main effect (all $F \mathrm{~s} \geq 28.06, p<.001$ ), with a Goals-Attitudes $\times$ Target interaction occurring in 8 of 12 samples (all significant $F \mathrm{~s} \geq 3.57, p<.05$ ).

The Goals-Attitudes main effect generally occurred because in 11 of 12 samples respondents viewed the United States (government and citizens averaged together) as more convinced of their own superiority than wanting to dominate other nations ( $t \mathrm{~s}>-2.28, p<.05)$ or (in all 12 samples) to promote human rights $(t \mathrm{~s}>-5.05, p<.001$. Further, the United States was generally viewed as desiring to dominate

TABLE 3

Mean Ratings of the Perceived Goals and Attitudes of the Government and Citizens of the United States

\begin{tabular}{|c|c|c|c|c|c|c|c|c|c|}
\hline \multirow[b]{2}{*}{ Nation } & \multicolumn{3}{|c|}{ Domination } & \multicolumn{3}{|c|}{ Human Rights } & \multicolumn{3}{|c|}{ U.S. Superiority } \\
\hline & Government & Citizens & $t$ & Government & Citizens & $t$ & Government & Citizens & $t$ \\
\hline Australia & 3.16 & 3.10 & .47 & 3.28 & 3.18 & .75 & 3.81 & 3.85 & -.23 \\
\hline Belgium & 3.52 & 3.11 & $4.00 * * *$ & 2.43 & 2.60 & $-2.26 * *$ & 3.73 & 3.67 & .51 \\
\hline Brazil & 3.85 & 3.69 & $2.03 * *$ & 2.31 & 2.55 & $-3.21 * * *$ & 4.07 & 4.10 & -.23 \\
\hline Chile & 3.71 & 3.44 & $5.93 * * *$ & 2.68 & 2.76 & $-1.77 *$ & 4.05 & 4.09 & -.58 \\
\hline England & 3.42 & 2.90 & $5.47 * * *$ & 2.77 & 3.05 & $-3.29 * * *$ & 3.94 & 3.77 & 1.55 \\
\hline Italy & 3.18 & 2.95 & $3.13 * * *$ & 2.44 & 2.59 & $-2.61 * * *$ & 3.28 & 3.39 & -1.32 \\
\hline Japan & 3.57 & 3.29 & $3.13 * * *$ & 2.84 & 2.90 & -.77 & 3.79 & 3.56 & $1.71 *$ \\
\hline Jewish Israeli & 3.48 & 3.07 & $5.49 * * *$ & 2.99 & 2.95 & .46 & 3.82 & 3.83 & -.16 \\
\hline Korea & 3.87 & 3.87 & -.06 & 2.25 & 2.32 & -.65 & 4.12 & 3.93 & 1.34 \\
\hline Palestinian Israeli & 4.30 & 3.90 & $5.21 * * *$ & 1.89 & 2.31 & $-4.77 * * *$ & 4.09 & 4.05 & .45 \\
\hline Taiwan & 3.54 & 3.46 & .97 & 3.30 & 3.39 & -1.00 & 3.94 & 3.94 & -.07 \\
\hline Turkey & 4.26 & 3.75 & $7.94 * * *$ & 2.10 & 2.41 & $-4.57 * * *$ & 4.23 & 4.18 & .61 \\
\hline$M$ & 3.66 & 3.38 & & 2.61 & 2.75 & & 3.91 & 3.86 & \\
\hline
\end{tabular}

Note. All ratings were made on a scale ranging from 1 (not at all) to 5 (extremely).

$* p<.10 . * * p<.05$. *** $p<.01$ 
other nations more than being concerned with others' human rights (11 of 12 samples: $t \mathrm{~s}>2.15, p<.05$ ). In summary, there was a strong consensus across nations that the government and citizens of the United States view their way of life as superior to all others. Respondents typically felt that this attitude characterizes the United States more than an active desire to dominate others; however, participants typically rated the United States as more interested in dominating other nations than in fostering others' human rights.

The Goals-Attitudes $\times$ Target interactions occurred because the U.S. government, as compared with its citizens, was often viewed as more focused on dominating other nations (9 of 12 samples; see Table 3 for contrasts) and was sometimes viewed as less concerned with human rights (5 of 12 samples, with marginal significance in the same direction in 1 other nation). Respondents viewed both the U.S. government and its citizens as equally strongly convinced that their nation's way of life is superior to others.

In summary, there was strong consensus that both the U.S. government and its citizens view the American way of life as superior (means typically approaching 4 on a 5-point scale) and (to a slightly lesser degree) seek to dominate other nations. Ratings of the United States' concern for others' human rights were significantly lower, and mean scores typically did not much exceed the neutral midpoint of the scale. These trends tended to be more extreme for ratings of the government than of citizens, but the overall patterns were similar.

The remaining analyses examine sections of the questionnaire for which the target was the United States as a whole (its government, people, culture) without distinctions between the government and its citizens. ANOVAs that included questionnaire version (whether the target in the first section was the U.S. government or citizens) as an independent variable revealed no effects on answers to the second sec- tion of the questionnaire. Therefore we collapsed across this factor for all analyses reported below.

\section{Status of the United States: Resources, Might, and Social Well-Being}

As the world's preeminent superpower, the United States would presumably be seen as possessing a great deal of resources (economic, technological) and might (military and political power) in comparison to other nations but not necessarily greater social well-being (especially by Western European participants, who generally claim a high quality of life and social services). One-way, repeated measures ANOVAs (status rating: resources, might, social well- being) were conducted within each sample (see Table 4 for means). Recall that these status ratings (unlike the other ratings) were made on a -3 (United States is far behind other nations) to +3 (United States is far ahead of other nations) scale.

In all samples, this analysis yielded a status rating main effect (all $F \mathrm{~s} \geq 207.36, p<.001$ ), which generally occurred because ratings for military might and economic resources were uniformly high, whereas ratings for social well-being were closer to the midpoint (0) of the scale. In every sample, the social well-being of the United States' citizens was rated as significantly lower than the United States' power in the world (all $t \mathrm{~s} \geq 16.81, p<.001$ ) and also as lower than the United States' economic resources (all $t \mathrm{~s} \geq 13.02, p<.001$ ). Respondents rated the United States' military power as higher than its resources in 9 of 12 samples (all significant $t \mathrm{~s}$ $\geq 2.99, p<.01$ ), whereas its resources were rated higher than its power in only one sample (Italy: $t=11.46, p<.001$ ).

In summary, there was strong consensus that the United States is extremely powerful (politically and militarily) and rich in resources (economic and technological) in comparison to other nations, but participants did not rate this power

TABLE 4

Means for Perceived U.S. Status Attributes and Responses to Afghanistan Invasion and 9/11

\begin{tabular}{|c|c|c|c|c|c|c|}
\hline \multirow[b]{2}{*}{ Nation } & \multicolumn{3}{|c|}{ U.S. Status Attributes } & \multicolumn{2}{|c|}{ Perception of Afghanistan Invasion } & \multirow[b]{2}{*}{ Upset Over 9/11 Attacks } \\
\hline & Resources & Power & Well-Being & Ulterior Motives & Justified Attack & \\
\hline Australia & 2.15 & 2.45 & .69 & 2.87 & 3.59 & 3.78 \\
\hline Belgium & 2.27 & 2.40 & -.43 & 3.33 & 2.95 & 3.54 \\
\hline Brazil & 2.38 & 2.41 & 1.32 & 3.39 & 2.74 & 3.53 \\
\hline Chile & 2.62 & 2.62 & 1.20 & 3.46 & 2.75 & 3.46 \\
\hline England & 2.26 & 2.20 & .72 & 3.11 & 3.49 & 3.84 \\
\hline Italy & 2.49 & 2.54 & -.09 & 2.89 & 2.66 & 3.66 \\
\hline Japan & 2.10 & 2.65 & .82 & 3.26 & 3.13 & 3.54 \\
\hline Jewish Israeli & 2.37 & 2.51 & .67 & 2.99 & 4.10 & 3.83 \\
\hline Korea & 2.18 & 2.35 & .77 & 3.66 & 2.70 & 3.05 \\
\hline Palestinian Israeli & 2.48 & 2.72 & 1.02 & 4.03 & 1.71 & 2.69 \\
\hline Taiwan & 2.21 & 2.75 & 1.47 & 3.18 & 3.61 & 3.51 \\
\hline Turkey & 2.52 & 2.65 & 1.35 & 3.28 & 2.65 & 3.31 \\
\hline$M$ & 2.34 & 2.52 & .79 & 3.29 & 3.01 & 3.48 \\
\hline
\end{tabular}

Note. Ratings of U.S. resources, power, and social well-being made on a-3 (United States far behind other nations) to +3 (United States far ahead of other nations) scale. All other ratings were made on a scale ranging from 1 (not at all) to 5 (extremely). 
and wealth as necessarily translating into a particularly high social well-being for its citizens.

\section{World Events: Perceptions of 9/11 and Military Response in Afghanistan}

How did respondents view the $9 / 11$ attacks on the United States and the subsequent military response in Afghanistan? A one-way, repeated measures ANOVA was performed within each sample to compare degree of upset over $9 / 11$ with competing perceptions of the Afghanistan invasion as justified response or Afghanistan invasion as reflecting ulterior motives. This analysis revealed a main effect in all 12 samples (all $F_{\mathrm{S}} \geq 16.63, p<.001$ ). See Table 4 for means.

Perceptions of the United States' invasion of Afghanistan differed in the various nations polled. In 8 of the samples, respondents more strongly endorsed the notion that the United States' invasion of Afghanistan had ulterior motives as compared with being justified; these contrasts were significant in 6 samples (Belgium, Brazil, Chile, Palestinians in Israel, Korea, Turkey: $t \mathrm{~s} \geq 7.82, p<.001)$ and marginally significant in 2 more (Italy, Japan:, $t \mathrm{~s} \geq 1.74, p<.10$ ). In contrast, respondents in 4 of the 12 samples collectively held the opposite view, rating "ulterior motives" lower than "justified response" ( $t \mathrm{~s} \leq-3.86, p<.01)$. Despite the often jaundiced view of the invasion of Afghanistan, 8 of the samples exhibited significantly greater upset over the $9 / 11$ attacks than suspicion of ulterior motives for the invasion of Afghanistan ( $t \mathrm{~s}$ $\leq-2.75, p<.01$ ), but this contrast was nonsignificant in the Chilean and Turkish samples and was significant in the opposite direction for Palestinians in Israel and Koreans (both $t \mathrm{~s} \geq$ $8.59, p<.01)$.

In summary, there was disagreement across samples about whether the United States' military response in Afghanistan was a product of ulterior motives (8 samples) or a matter of legitimate self-defense (4 samples). Ratings of upset over the
9/11 attacks were generally high, but respondents in some samples (Palestinians in Israel, Koreans) indicated relatively lower levels of upset over 9/11 and significantly more suspiciousness concerning the United States' actions in Afghanistan.

\section{Perceived Intent to Dominate as a Predictor of Perceptions of the United States}

According to both the SCM and IT, the cooperative or competitive (dominative, exploitative) intent of the United States toward other nations ought to predict its perceived warmth (warmth, arrogance, goals and attitudes toward other nations, intentions in Afghanistan), related emotions (admiration, contempt), and intentions (concern for human rights, reasons for invading Afghanistan). In contrast, the SCM predicts that perceptions of whether the United States' orientation toward other nations is dominative versus cooperative ought to be unrelated to perceptions of its competence and power, which are predicted to be determined by perceived status (not cooperativeness).

The measure that most directly captures perceptions of whether the United States takes a competitive, dominative, exploitative (vs. cooperative) orientation toward the rest of the world was the Desire to Dominate scale. Correlations of this scale with the perceived traits, emotions, goals, resources, and intentions of the United States are reported in Table 5. Because correlations between desire for dominance and other ratings were similar regardless of whether the target was the U.S. government or its citizens, we do not present separate correlations for each target.

Perceived intent to dominate predicted warmth but not competence ratings. As expected, participants who perceived the United States as generally desiring to dominate other nations viewed the United States as significantly less warm and more arrogant in every sample (see Table 5). These correla-

TABLE 5

Correlations of Perceived Intent to Dominate With Trait and Emotion Ratings

\begin{tabular}{|c|c|c|c|c|c|c|}
\hline \multirow[b]{2}{*}{ Nation } & \multicolumn{3}{|c|}{ Traits } & \multicolumn{3}{|c|}{ Emotions } \\
\hline & Warmth & Competence & Arrogance & Admiration & Contempt & Envy \\
\hline Australia & $-.51 * * *$ & -.03 & $.60 * * *$ & $-.34 * * *$ & $.52 * * *$ & .07 \\
\hline Belgium & $-.51 * * *$ & -.07 & $.61 * * *$ & $-.42 * * *$ & $.59 * * *$ & -.06 \\
\hline Brazil & $-.33 * * *$ & $-.15 * *$ & $.55 * * *$ & $-.21 * * *$ & $.29 * * *$ & -.05 \\
\hline Chile & $-.38 * * *$ & -.17 & $.54 * * *$ & $-.29 * * *$ & $.47 * * *$ & .01 \\
\hline England & $-.59 * * *$ & $-.27 * * *$ & $.67 * * *$ & $-.47 * * *$ & $.60 * * *$ & -.08 \\
\hline Italy & $-.36 * * *$ & .05 & $.60 * * *$ & $-.36 * * *$ & $.51 * * *$ & -.06 \\
\hline Japan & $-.40 * * *$ & .03 & $.58 * * *$ & $-.27 * * *$ & $.44 * * *$ & -.02 \\
\hline Jewish Israeli & $-.47 * * *$ & .08 & $.58 * * *$ & $-.43 * * *$ & $.60 * * *$ & $.13 * *$ \\
\hline Korea & $-.50 * * *$ & -.13 & $.59 * * *$ & $-.35 * * *$ & $.56^{* * * *}$ & .09 \\
\hline Palestinian Israeli & $-.58 * *$ & $-.17 * * *$ & $.62 * * *$ & $-.44 * * *$ & $.60 * * *$ & .02 \\
\hline Taiwan & $-.46 * * *$ & -.10 & $.63 * * *$ & $-.26 * * *$ & $.43 * * *$ & .18 \\
\hline Turkey & $-.50 * * *$ & .06 & $.55 * * *$ & $-.27 * * *$ & $.45 * * *$ & .04 \\
\hline All participants & $-.51 * * *$ & $-.03 * *$ & $.60 * *$ & $-.34 * * *$ & $.52 * * *$ & $.07 * * *$ \\
\hline
\end{tabular}

$* * p<.05 . * * * p<.01$. 
tions were generally strong (across all participants: $r=-.51$ for warmth and $r=.60$ for arrogance) and were significant in all samples. In contrast, and as predicted, perceiving the United States as desiring to dominate did not consistently predict ratings of competence. Dominance-competence correlations were statistically significant in some samples, but were generally of low magnitude; because of the extremely large sample size, this correlation was statistically significant when computed across all participants but was of trivial magnitude $(r=-.03)$.

Perceived intent to dominate predicts emotions toward the United States. As expected (see Table 5), respondents who perceived the United States as desiring to dominate other nations were significantly less likely to indicate admiration and more likely to indicate contempt toward the United States in all of the samples studied. In contrast, perceived intent of the United States to dominate other nations did not predict expressions of envy.

Perceived intent to dominate predicts United States' perceived goals and attitudes. Table 6 reveals that, consistent with expectations, respondents who perceived the United States as desiring to dominate other nations also tended to view the United States as being less concerned with human rights and more convinced of the superiority of its own way of life. These correlations were in the same direction and statistically significant in every sample.

Perceived intent to dominate predicts upset over 9/11 and reactions to invasion of Afghanistan. As Table 6 also reveals, within each sample, people who viewed the United States as trying to dominate other nations were significantly less likely to be upset over the 9/11 attack (all samples), more likely to view the invasion of Afghanistan as being based on ulterior motives (all samples), and less likely to see the invasion of Afghanistan as a justified response to the 9/11 attacks (in 11 of 12 samples).

Perceived intent to dominate does not predict status indicators. If ratings of resources, power, and social well-being are viewed as indicators of the United States' perceived status and power, the SCM also predicts that these ratings (like competence ratings) ought to be unrelated to the United States' perceived cooperativeness or competitiveness toward other nations. Within samples, the correlations between perceptions of the United States' desire to dominate other nations and these status and power indicators were weak and generally nonsignificant (see Table 6). Resources and power were seldom significantly correlated to perceived intent to dominate (and in the few samples where they were, the correlations were slight). In six samples, there were significantly negative correlations of perceived intent to dominate with the perceived social well-being of Americans, but even the highest of these was a modest .35. Overall, when averaged across all participants, although the correlations were statistically significant because of the large sample size, they were of trivial magnitude ( $r=.06$ for economic and technological resources; $r=.13$ for military and economic power; and $r=-.07$ for social well-being).

\section{DISCUSSION}

Overall, the United States was admired and held in contempt in almost equal measure by respondents in most of the nations surveyed here. Perceptions of the traits, goals and attitudes, resources and power, and, most importantly, the degree to which the United States is viewed as seeking to dominate other nations suggest why this is the case: The

TABLE 6

Correlations of Perceived Intent to Dominate With U.S. Goals/Attitudes, Responses to Afghanistan Invasion and 9/11 Attack

\begin{tabular}{|c|c|c|c|c|c|c|c|c|}
\hline \multirow[b]{2}{*}{ Nation } & \multirow[b]{2}{*}{$\begin{array}{c}\text { U.S. Wants } \\
\text { Human Rights }\end{array}$} & \multirow[b]{2}{*}{$\begin{array}{c}\text { U.S. Sees Self } \\
\text { as Superior }\end{array}$} & \multirow[b]{2}{*}{$\begin{array}{l}\text { Upset Over } \\
\text { 9/11 Attacks }\end{array}$} & \multicolumn{2}{|c|}{ Afghanistan Invasion } & \multicolumn{3}{|c|}{ U.S. Status Attributes } \\
\hline & & & & $\begin{array}{l}\text { Ulterior } \\
\text { Motive }\end{array}$ & Justified & Resources & Power & Well-Being \\
\hline Australia & $-.46 * * *$ & $.54 * * *$ & $-.42 * * *$ & $.45 * * *$ & $-.30 * * *$ & .09 & .15 & -.13 \\
\hline Belgium & $-.45^{* * *} *$ & $.61 * * *$ & $-.41 * * *$ & $.33 * * *$ & $-.25 * * *$ & .03 & .09 & $-.32 * * *$ \\
\hline Brazil & $-.38 * * *$ & $.58 * * *$ & $-.16 * * *$ & $.37 * * *$ & $-.05 * * *$ & $.21 * * *$ & $.11 * *$ & -.02 \\
\hline Chile & $-.40 * * *$ & $.47 * * *$ & $-.43 * * *$ & $.47 * * *$ & $-.26 * * *$ & -.03 & $.07 * *$ & $-.21 * * *$ \\
\hline England & $-.57 * * *$ & $.64 * * *$ & $-.45 * * *$ & $.48 * * *$ & $-.26 * * *$ & .06 & $.12 * *$ & $-.29 * * *$ \\
\hline Italy & $-.28 * * *$ & $.50 * * *$ & $-.25 * * *$ & $.34 * * *$ & $-.40 * * *$ & .06 & .03 & $-.35 * * *$ \\
\hline Japan & $-.24 * * *$ & $.55 * * *$ & $-.14 * *$ & $.40 * * *$ & -.02 & .05 & $.13^{* *}$ & -.12 \\
\hline Jewish Israeli & $-.46^{* * * *}$ & $.54 * * *$ & $-.25 * * *$ & $.41 * * *$ & $-.17 * * *$ & .01 & .00 & $-.21 * * *$ \\
\hline Korea & $-.63 * * *$ & $.43 * * *$ & $-.34 * * *$ & $.24 * * *$ & $-.25 * *$ & .04 & .07 & -.07 \\
\hline Palestinian Israeli & $-.62 * * *$ & $.53 * * *$ & $-.41 * * *$ & $.43 * * *$ & $-.36 * * *$ & .11 & $.13 * * *$ & $.15 * * *$ \\
\hline Taiwan & $-.39 * * *$ & $.59 * * *$ & $-.29 * * *$ & $.56 * * *$ & $-.14 * *$ & .05 & .04 & $-.22 * *$ \\
\hline Turkey & $-.54 * * *$ & $.47 * * *$ & $-.34 * * *$ & $.32 * * *$ & $-.22 * * *$ & .07 & .08 & -.11 \\
\hline All participants & $-.46^{* * *} *$ & $.54 * * *$ & $-.42 * * *$ & $.45 * * *$ & $-.30 * * *$ & $.06 * * *$ & $.13 * * *$ & $-.07 * * *$ \\
\hline
\end{tabular}

$* * p<.05 . * * * p<.01$. 
United States is admired for its perceived prowess and competence but is disparaged because of suspicions that its true goals are domination and exploitation rather than the promotion of human rights and liberty. The general picture that emerged (even among allies such as Australia and England) is a nation perceived to be competent but arrogant, convinced of its own superiority, and desirous of dominating and exploiting other nations more than promoting human rights. These perceptions did not preclude generally high upset over the 9/11 attacks on the United States, but the subsequent invasion of Afghanistan was regarded with a jaundiced eye by respondents in most of the samples (except the Australian, English, Jewish Israeli, and Taiwanese) as reflecting ulterior motives more than being a justified response to the $9 / 11$ attacks.

Respondents did distinguish between the U.S. government and its citizens. For those sections that specifically asked respondents to consider either the government or the citizens of the United States, impressions of the government evinced a more extreme version of the image described above. Specifically, compared with its citizens, the U.S. government tended to be seen as less warm and more arrogant (in almost all samples) as well as (in some samples) more competent. The U.S. government was viewed as more intent on dominating other nations (most samples) and less concerned with fostering human rights (in half of the samples) than were its citizens. Respondents in most samples correspondingly expressed more contempt and, in some samples, less admiration for the U.S. government than for its citizens. Note, however, that these differences (even when statistically significant) tended to be small. In general, the U.S. government and its citizens tended (in broad strokes) to be tarred by the same brush.

The competent, but not warm perception of the United States accords with what the SCM predicts for a high-status group that is perceived to compete with (or to exploit) other groups. Similarly, the perception of arrogance is consistent with what IT characterizes as an "imperialist image." These theories both suggest that high-status, powerful groups will not be perceived as cold and arrogant if they are viewed as having cooperative goals. Unfortunately, in most samples, the United States was perceived as seeking world domination.

The SCM further predicts that the emotional reaction to a high-status group perceived to have a competitive orientation toward others mixes admiration (for the group's competence and success) with hostility (for its perceived exploitation). Consistent with this idea, the emotion ratings generally showed an equal mix of admiration and contempt toward the United States. The SCM also predicts that high-status, competitive groups are envied, but self-reported envy (toward the United States) was generally low. Because envy implies lower status for the self (Smith, 1991), it may not have been found here because people are generally reluctant to report experiencing it. For instance, Spears and Leach (2004) found that manipulations designed to elicit envy affected self-reports only when participants believed that a putative lie detector would reveal the truthfulness of their answers. Alternatively, negative emotions toward the United States may more simply represent, as IT would suggest, a straightforward resentment of America's foreign policies, which are perceived as exploitative and an abuse of power.

As both the SCM and IT suggest, the perceived degree to which the United States is viewed as desiring to dominate other nations powerfully predicts a variety of reactions to the United States. Specifically, perceptions of the United States' intent to dominate predicted viewing the United States as less warm and more arrogant, being less interested in promoting human rights, less sympathetic reactions to the 9/11 attacks, and greater suspiciousness that the invasion of Afghanistan reflected ulterior motives.

In contrast, the SCM suggests that perceptions of competence are not determined by perceived cooperation and competition but by status and power. Perceptions of competence (of both the government and the citizens of the United States) were uniformly high across samples, in accordance with its status as the sole global "hyperpower." Moreover, the trait ratings of competence and status-related ratings (e.g., resources, power) were not meaningfully correlated to perceptions of the United States' as seeking to dominate other nations (whereas ratings of warmth and arrogance were strongly related to the United States' perceived intent).

Caution must be exercised, however, in interpreting comparisons across scales (e.g., competence and warmth) that do not possess ratio properties. It may be particularly problematic to compare across subjectively positive and negative scales given the people's general reluctance to assign negative characteristics to other people and groups (Matlin \& Stang, 1978). In light of this bias, however, the willingness of respondents to assign overtly negative characteristics (e.g., arrogance) to the United States (including its citizens) is especially troubling. Moreover, the Pew polls suggest that anti-American sentiment has only increased since 2002 when our data were obtained.

It is also important to keep in mind that the samples in the current study were not representative of their nations but were confined to college student participants. Nevertheless, the results are consistent with the Pew surveys, which have obtained random samples. Further, as noted earlier, college students are arguably an important group to study in this context because they represent the future elites and opinion leaders of their nations and, when radicalized, are more likely to form the leadership of groups that oppose, or even commit terrorist attacks against, the United States (Amant, 2001).

Although we did not examine American college students' attitudes, it is reasonable to suppose that their attitudes have been affected by awareness of global anti-Americanism. The world is now connected by instant communication technologies and many American college students travel or study abroad; they also interact with international students who 
study in the United States. Indeed, a recent survey of Princeton University students suggests not only that they recognize that foreigners have unfavorable views of America but also that their own views of Americans are more negative than those they believe the majority of Americans to hold (Leslie, Constantine, Fiske, Dunham, \& Banaji, 2005). These data culminate 7 decades of periodic surveys of Princeton students' views of Americans and nine other national or ethnic groups (beginning with Katz \& Braly, 1933) that show a steady erosion in ratings of Americans, from being the most favorably viewed group to being rated lower than the formerly most negatively viewed groups (e.g., the Turks and the Chinese). Thus, to some extent, American students' image of their own national group may mirror the more general increase in anti-American sentiment that the current study and opinion polls have documented.

Another limitation of the current study is its correlational design. We cannot conclude from these data whether perceptions of intentions causally determined the favorability (or unfavorability) of impressions of the United States. However, recent tests of the SCM that have used fictional groups (so that status and competitiveness can be manipulated) support the model's proposed causal sequence from structural variables (status, interdependence) to traits (warmth, competence) and emotions (Cuddy, Fiske, \& Glick, in press). Further, manipulations of cooperation and competition have long been known to be strong determinants of intergroup relations (Sherif, Harvey, White, Hood, \& Sherif, 1961; Tajfel \& Turner, 1979), making it likely that perceptions of the United States' goals toward other nations are, at least in part, a cause of respondents' impressions. Unfortunately, once suspicions of malevolent intentions become entrenched, they may become quite difficult to alter because even apparently benign actions may be explained as masking ulterior motives. For instance, all foreign aid given by the United States may be viewed as an attempt to buy influence, rather than as reflecting even a hint of humanitarianism. In the current study, Palestinians in Israel and the Turkish sample showed the greatest degree of conviction that the United States acts out of self-interested and hostile motives, reflecting deepseated suspicion of its motives.

Although there were differences across nations in how the United States is perceived, the more striking finding was the degree of cross-national similarity in how America is characterized. Even among college students in nations considered to be allies of the United States, America tended to be perceived as competent but arrogant and dominance-seeking. We leave the debate of the accuracy or inaccuracy of this characterization to others. From a security standpoint, however, the consistency with which this view is endorsed across nations is both striking and troubling. It is easy to construct psychological justifications for attacking powerful groups that are perceived as intentionally seeking to exploit or to harm others (e.g., Glick, 2005). A broad social consensus in the wider world that the United States fits such a category does not bode well either for the future likelihood of terrorist attacks or for the sympathetic cooperation of historic allies.

\section{REFERENCES}

Alexander, M. G., Brewer, M. B., \& Herrmann, R. K. (1999). Images and affect: A functional analysis of out-group stereotypes. Journal of Personality and Social Psychology, 77, 78-93.

Amant, A. (2001). Empowered through violence: The reinventing of Islamic extremism. In S. Talbott \& N. Chanda (Eds.), The age of terror. New York: Basic Books.

Asch, S. E. (1946). Forming impressions of personality. Journal of Abnormal and Social Psychology, 41, 1230-1240.

Cuddy, A. J. C., Fiske, S. T., \& Glick, P. (in press). The BIAS Map: Behaviors from Intergroup Affect and Stereotypes. Journal of Personality and Social Psychology.

Cuddy, A. J. C., Fiske, S. T., Kwan, V. S. Y., Glick, P., Demoulin, S., Leyens, J.-Ph., et al. (in press). Is the stereotype content model culture-bound? A cross-cultural comparison reveals systematic similarities and differences. British Journal of Social Psychology.

Glick, P. (2005). Choice of scapegoats. In J. F. Dovidio, P. Glick, \& L. A Rudman (Eds.), On the nature of prejudice: 50 years after Allport. (pp. 244-261). Malden, MA: Blackwell Publishing.

Fiske, S. T., Cuddy, A. J. C., Glick, P., \& Xu, J. (2002). A model of (often mixed) stereotype content: Competence and warmth respectively follow from perceived status and competition. Journal of Personality and Social Psychology, 82, 878-902.

Friedman, T. L. (2002). Longitudes and attitudes: Exploring the world after September 11. New York: Farrar, Strauss \& Giroux.

Katz, D., \& Braly, K. W. (1933). Racial stereotypes of one hundred college students. Journal of Abnormal and Social Psychology, 28, 280-290.

Leslie, L., Constantine, V., Fiske, S. T., Dunham, Y., \& Banaji, M. (2005). The Princeton Quartet: Ambivalence moderates stereotype content over time. Unpublished manuscript, Princeton University.

Matlin, M. W., \& Stang, D. J. (1978). The Pollyanna principle. Cambridge, MA: Schenkman.

Pew Global Attitudes Project. (2002). What the world thinks in 2002. Washington, DC: Pew Research Center for the People and the Press.

Pew Global Attitudes Project. (2004). A year after Iraq war: Mistrust of America ever higher, Muslim anger persists. Washington, DC: Pew Research Center for the People and the Press.

Sherif, M., Harvey, L. J., White, B. J., Hood, W. R., \& Sherif, C. W. (1961) The Robbers Cave Experiment: Intergroup conflict and cooperation. Middletown, CT: Wesleyan University Press.

Smith, R.H. (1991). Envy and the sense of injustice. In P. Salovey (Ed.), The psychology of jealousy and envy (pp. 79-99). New York: Guilford Press.

Spears, R., \& Leach, C. (2004). Intergroup Schadenfreude through the bogus pipeline: A portal to the pleasure and the pain. Unpublished manuscript, Cardiff University.

Tajfel, H., \& Turner, J.C. (1979). An integrative theory of intergroup conflict. In W. G. Austin \& S. Worchel (Eds.), The social psychology of intergroup relations (p. 33-47). Monterey, CA: Brooks/Cole. 